\title{
Food protein-induced enterocolitis syndrome: a large French multicentric experience
}

\author{
Anaïs Lemoine ${ }^{1}$, Anne-Sophie Colas ${ }^{1}$, Sebastien LE $^{2}$, Christophe Delacourt ${ }^{2}$, Patrick \\ Tounian $^{1}$, and Guillaume LEZMI ${ }^{2}$ \\ ${ }^{1}$ AP-HP, Trousseau Hospital \\ ${ }^{2}$ AP-HP, Hôpital Necker-Enfants Malades
}

April 20, 2021

\begin{abstract}
Background Food protein-induced enterocolitis syndrome (FPIES) is a non IgE-mediated food allergy, with potential dehydration secondary to vomiting. Differences exist regarding culprit foods, onset symptoms, and age of tolerance depending on the country of origin. We aimed to describe the characteristics of a French population of children with FPIES. Methods Data from 179 children who were referred for acute or chronic FPIES in two pediatric tertiary centers between 2014 and 2020 were retrospectively collected. The diagnosis of FPIES was based on international consensus guidelines. Clinical characteristics, culprit food and age at resolution were assessed. Results In the 192 described FPIES, the age at first symptoms was 5.8 months old. The main offending foods were cow's milk (60.3\%), hen's egg $(16.2 \%)$, and fish $(11.7 \%)$. Single FPIES was observed in $94.4 \%$ and multiple FPIES in $5.6 \%$ of cases. The age at resolution of FPIES was 2.2 years old, and resolution occurred later for fish than for milk (2.9 years versus 2.0, $\mathrm{p}=0.01$ ). Severe acute FPIES was a risk factor for delayed resolution (relative risk: $3.3[1.2-9.2]$ ), but not IgE sensitization. Performing an oral food challenge within 12 months after the first reaction increased the risk of failure (RR: 2.0 [1.2-3.5]). Conclusion In this French cohort of children with FPIES, the main culprit foods were ubiquitous. Rice, oat and soy were rarely or not involved. Multiple FPIES was infrequent. Our data confirmed the overall good prognosis of FPIES, the later resolution of FPIES to fish and in the case of severe acute FPIES.
\end{abstract}

\section{Food protein-induced enterocolitis syndrome: a large French multicentric experience}

Short title: Characteristics of FPIES in French children

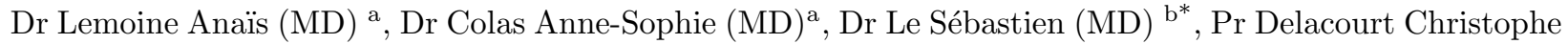
$(\mathrm{MD}, \mathrm{PhD})^{\mathrm{b}}$, Pr Tounian Patrick $(\mathrm{MD}, \mathrm{PhD})^{\mathrm{a}}{ }^{\mathrm{a}}$, Dr Lezmi Guillaume $(\mathrm{MD}, \mathrm{PhD})^{\mathrm{b}}$

\section{Institutional affiliations:}

Department of Pediatric Nutrition and Gastroenterology, Trousseau Hospital, AP-HP, Sorbonne Université, Paris, France

Department of Pediatric Pneumology and Allergology, Necker-Enfants Malades Hospital, AP-HP, Université Paris Descartes, Paris, France

* Department of Pediatric and Emergency Unit, Louis Mourier Hospital, AP-HP, Université de Paris, Paris, France

Corresponding author: Dr Lemoine Anaïs, Trousseau Hospital, Department of Pediatric Nutrition and Gastroenterology, 26 avenue du Dr Arnold Netter, 75012 PARIS, France. E-mail address: anais.lemoine@aphp.fr

Word count: 2499; tables : 3 ; figures : 3 
Authors' Contribution statement: Anaïs Lemoine:conceptualization (equal); data curation (lead); formal analysis; investigation (equal); supervision (equal); visualization; writing - original draft (lead); writing - review and editing (equal) -Anne-Sophie Colas : data curation (equal); investigation (equal); writing review and editing (equal); Sébastien Le : data curation (equal); ; investigation (equal); writing - review and editing (equal); Delacourt Christophe: conceptualization (supporting); writing - review and editing (equal); Tounian Patrick : writing - review and editing (equal); Lezmi Guillaume: conceptualization (equal); investigation (equal); supervision (equal); writing - original draft (supporting); writing - review and editing (equal)

\section{Conflict of interests : none}

\section{Funding sources: none}

\section{Abstract \\ Background}

Food protein-induced enterocolitis syndrome (FPIES) is a non IgE-mediated food allergy, with potential dehydration secondary to vomiting. Differences exist regarding culprit foods, onset symptoms, and age of tolerance depending on the country of origin. We aimed to describe the characteristics of a French population of children with FPIES.

\section{Methods}

Data from 179 children who were referred for acute or chronic FPIES in two pediatric tertiary centers between 2014 and 2020 were retrospectively collected. The diagnosis of FPIES was based on international consensus guidelines. Clinical characteristics, culprit food and age at resolution were assessed.

\section{Results}

In the 192 described FPIES, the age at first symptoms was 5.8 months old. The main offending foods were cow's milk (60.3\%), hen's egg (16.2\%), and fish (11.7\%). Single FPIES was observed in $94.4 \%$ and multiple FPIES in $5.6 \%$ of cases. The age at resolution of FPIES was 2.2 years old, and resolution occurred later for fish than for milk (2.9 years versus 2.0, $\mathrm{p}=0.01$ ). Severe acute FPIES was a risk factor for delayed resolution (relative risk: 3.3 [1.2-9.2]), but not IgE sensitization. Performing an oral food challenge within 12 months after the first reaction increased the risk of failure (RR: 2.0 [1.2-3.5]).

\section{Conclusion}

In this French cohort of children with FPIES, the main culprit foods were ubiquitous. Rice, oat and soy were rarely or not involved. Multiple FPIES was infrequent. Our data confirmed the overall good prognosis of FPIES, the later resolution of FPIES to fish and in the case of severe acute FPIES.

Keywords: children; FPIES; France; severity; tolerance

\section{Key messages:}

We described the largest French cohort of children with food protein-induced enterocolitis syndrome to date. The top 3 culprit foods were milk, eggs and fish. The overall resolution age was 2.2 years.

Severe acute food protein-induced enterocolitis syndrome and food protein-induced enterocolitis syndrome to seafood products were associated with an increased risk of delayed acquisition of tolerance, but not IgE sensitization.

\section{Main Text}

\section{Introduction}

Food protein-induced enterocolitis syndrome (FPIES) is a non IgE-mediated food allergy. Its incidence is estimated between $0.015-0.7 \% .{ }^{1-4}$ In the absence of biomarkers, the diagnosis of FPIES is based only on 
clinical presentation. Acute FPIES is defined by typical repetitive vomiting starting 1 to 4 hours after ingestion of the culprit food, in association with at least 3 minor criteria according to the international consensus guidelines for the diagnosis. ${ }^{5}$ Chronic FPIES occurs when the food is regularly consumed. Diagnosis is based on the presence of intermittent emesis, chronic diarrhea, poor weight gain, which improve after several days to weeks of exclusion of the offending food. After a period of avoidance, acute typical symptoms occur upon reexposure. ${ }^{6}$ Oral food challenges (OFC) are useful in doubtful cases to confirm the diagnosis and to test the acquisition of tolerance. ${ }^{5}$ The offending foods depend on geographic origins. ${ }^{6}$ Resolution of FPIES is expected by school age in the majority of cases. ${ }^{6}$

In this study we aimed to describe FPIES in a large population of French children, using international diagnosis criteria, ${ }^{5}$ and to describe its natural history.

\section{Methods}

Subjects

Data from children with FPIES, referred consecutively to two pediatric French centers (Trousseau and Necker-Enfants Malades, Paris) between January 2014 and April 2020, were retrospectively collected. Clinical data related to FPIES were collected: age at onset of first symptoms, at diagnosis, at OFC, at acquisition of tolerance, culprit food(s), symptoms, personal and familial first-degree relative history of atopic disease (IgE-mediated food allergy, allergic rhinoconjunctivitis, asthma, atopic dermatitis, positive skin prick test (SPT), positive specific $\operatorname{IgE}>0.35 \mathrm{kU} / \mathrm{L}$ ).

The study was approved by the French Pediatric Hepato-Gastroenterology and Nutrition's Ethics Committee.

Definitions

The diagnosis of acute FPIES was confirmed if recurrent vomiting was associated with at least 3 minor criteria, ${ }^{5}$ or in the presence of typical vomiting after performance of an OFC. ${ }^{5}$ The diagnosis of acute FPIES waspresumptive when the recurrent vomiting was associated with only 2 minor criteria, in the absence of skin or respiratory symptoms, and without any argument for a differential diagnosis. ${ }^{5,6}$

The diagnosis of chronic FPIES was confirmed in the presence of acute-on-chronic typical symptoms. ${ }^{5}$ The diagnosis of chronic FPIES was considered to be presumptive in the absence of any acute phase, in children with compatible symptoms, including chronic diarrhea, vomiting, with significant improvement within a few days after avoidance of the offending food, and after exclusion of differential diagnosis. ${ }^{5,6}$ When the diagnosis criteria of FPIES were lacking, children were excluded from the study.

Multiple FPIES was defined as FPIES to several different groups of foods, as opposed to single FPIES.

Solid foods referred to food other than mammal's milk.

Acute FPIES was defined as severe if the patient had needed a rapid vascular filling and/or hospitalisation due to dehydration or hypovolemic shock, persistent hypotonia or malaise.

Persistent FPIES was defined as FPIES without the acquisition of tolerance at the end of the follow-up and after at least one year after the first symptoms.

\section{Oral Food Challenges}

OFCs were performed to assess FPIES resolution, in medical day units. Children were considered to be tolerant if no symptoms occurred within 4 hours after ingestion of the food in question, and they were able to tolerate one age-appropriate serving regularly at home. We took into account the successful reintroduction performed at home (accidental or voluntary exposure). An OFC failure was diagnosed in the case of recurrence of vomiting, even if isolated.

Statistical analyses 
Continuous values were expressed as median and interquartile range (IQR) values, or in raw values with a percentage. All statistical analyses and figures were performed using GraphPad Prism version 5.3 for Windows. A p-value $<0.05$ was considered to be significant. In Kaplan-Meier survival analyses, the nontolerant patients were censored at the age of the last follow-up (OFC, consultation or last attempt at a phone call if contact lost, as a follow-up).

\section{Results}

\section{General characteristics of the population}

One hundred and seventy-nine $(\mathrm{n}=179)$ children with FPIES were included. The female to male ratio was 0.88 ( $53.1 \%$ of boys) (Table I). The median age at the onset of the first symptoms of FPIES was 5.8 months (3.0-8.0) and was younger for CM than for solid foods (Table II). Personal and familial histories of atopic disease are presented in Table I.

\section{FPIES characteristics}

A total of 192 FPIES cases were reported. The diagnosis of FPIES wasconfirmed in 151 cases and was presumptive in 41 cases (Table III). Children with confirmed or presumptive FPIES did not differ in terms of sex ratio, atopic status, age at tolerance or tolerance rate (Table III).

Children with acute FPIES had a mean of 3.3 minor criteria (maximum: 7). The most frequent minor criteria were recurrent episodes of repetitive vomiting after eating the same culprit food $(84.8 \%)$, followed by lethargy (74.5\%), pallor $(53,1 \%)$, the need for an emergency department visit $(37.9 \%)$, diarrhea $(33.1 \%)$, the need for intravenous fluid support (27.6\%), vomiting after eating a different food (19.3\%), and hypotension (4.1\%). Hypothermia was not recorded. Lethargy, pallor, emergency department visit, and intravenous fluid support were more often found in confirmed FPIES $(\mathrm{p}<0.01)$ (Table III).

Thirteen children (7.3\%) experienced severe confirmed acute FPIES (Table III). Two patients required hospitalization in an intensive care unit owing to severe dehydration following ingestion of CM. Eleven patients needed rapid vascular filling during an OFC.

A total of 47 children (26.1\%) had chronic FPIES, and CM was the only elicitor of chronic FPIES.

One hundred and sixty-nine (94.4\%) children had single FPIES, and $10(5.6 \%)$ had multiple FPIES. CM was involved in 108 children (60.3\%), hen's egg in 29 (16.2\%), and fish in 21 (11.7\%) (Figure 1). Among the 10 multiple FPIES cases reported, CM was involved in 6 cases. One child had FPIES to 4 foods (CM, chicken, hen's egg, and green beans), another one to 3 foods (CM, hen's egg, maize), and 8 to 2 foods: CM and beef/veal $(\mathrm{n}=2), \mathrm{CM}$ and soy, CM and raspberry, rice and hen's egg, rice and banana, coconut and tomato, avocado and cashew nuts.

\section{IgE sensitization}

IgE sensitization to the culprit food was found in 28/180 FPIES (14.7\%) (Table I). One child developed an IgE-mediated allergy with the culprit food over time. By contrast, a child with a history of IgE-mediated allergy to CM at the age of 1 month, switched to FPIES to CM after 9 months of age with negative $\operatorname{IgE}$ at this time.

\section{$O F C$}

Two hundred and twelve $(\mathrm{n}=212)$ OFCs were performed to assess tolerance. A first OFC was performed in 173 children at 2.0 years of age (1.5-2.9), with a success rate of $74.0 \%$. The interval between two OFCs was 11.7 months (7.0-15.8). In 19 cases of FPIES (12 with confirmed acute FPIES, 2 with confirmed chronic FPIES, 4 with presumptive acute FPIES, and 1 with chronic FPIES), patients reintroduced the food on their own, without any reaction, at a median age of 2.7 years (2.2-3.3).

For milk, the first OFC was performed earlier than for other foods $(\mathrm{p}<0.001)$, fish $(\mathrm{p}<0.001)$, meat and vegetables/legumes/fruits $(\mathrm{p}<0.01)$ (Table II). 


\section{Evolution and Risk factor of failure of OFCs or prolonged FPIES}

At the time of the last review of medical records, 151 out of 192 culprit foods were successfully reintroduced (78.6\%). Eighty-eight percent of children with FPIES to CM were tolerant, as were $82.8 \%$ of those reactive to hen's eggs, and $52.4 \%$ to fish (Table II). Among the tolerant patients, the overall age of tolerance was 2.2 years of age (1.7-3.0, $\mathrm{n}=150)$. Kaplan Meier curves showed an overall median survival of FPIES at 2.5 years of age, with a global resolution rate of $80.1 \%$ at 5 years of age (Figure 2). The resolution rate at 5 years of age was higher for FPIES to CM than to fish, and was similar for FPIES to CM and hen's egg (Figure 3).

Performing a reintroduction within the 12 months after the onset of FPIES was associated with an increased risk of failure of an OFC (RR: $2.0[1.2-3.5])$, particularly in children with a severe form of FPIES $(\mathrm{p}<0.001)$.

Severe acute reactions increased the risk of persistent FPIES (RR: 3.3 [1.2-9.2]). Six patients with a history of severe reactions out of $13(46.2 \%)$ were not tolerant after a median duration of up to 4.3 years of age. The 7 other patients were tolerant at 2.3 years of age.

IgE sensitization against the culprit food was not associated with a longer duration of FPIES among tolerant patients $(\mathrm{p}=0.3)$ and was not a risk factor of failure to an OFC (RR: $0.8[0.3-2.0])$.

Neither personal nor familial atopic history were risk factors of persistent FPIES ( $\mathrm{p}=0.15$ and 0.9 respectively).

\section{Discussion}

In this study, we described the characteristics of a large population of 179 French children with FPIES according to international guidelines. We found that i) culprit foods were ubiquitous as in other international cohorts, but some specific characteristics existed, ii) persistent FPIES was more frequent for fish than for other foods, and in case of severe acute FPIES, but IgE sensitization was not associated with longer duration of FPIES, iii) performing OFC within 12 months after the first reaction increased the risk of failure.

In our study, the main culprit food was CM, followed by hen's egg, and fish, which differs from the findings in other countries. ${ }^{7-12}$ The most frequent culprit food was fish in Greece ${ }^{13}$ and Spain ${ }^{10,14}$ rice in Australia ${ }^{15-17}$ and the USA, ${ }^{18}$ and oats in Taiwan. ${ }^{19}$ Soy is frequently reported as a trigger food by North American, British, Australian and Israeli cohorts ${ }^{4,17,20,21}$ and was infrequent in our population. Food habits, geographic origins, genetic factors, microbiota, and other environmental pre- or postnatal factors may explain these differences. ${ }^{1,21}$

The overall age of resolution of FPIES was 2.2 years of age for all foods. The age at resolution was based on the day of performance of an OFC and thus may be overestimated. Previous studies suggested that the later age of tolerance relates to the ingestion of seafood products $6,9,17,22$ and may occur more frequently in cases of multiple FPIES. ${ }^{6}$ Resolution of FPIES to fish is around $18.8 \%$ to $57.0 \%$ of cases between 3 to 4.5 years of age. ${ }^{13,16,22,23}$ We found a similar rate of $38 \%$ tolerance at 4.0 years of age, with an older age of resolution for fish than CM. Due to the low prevalence of multiple FPIES in our cohort, we were unable to compare the age of resolution of single and multiple FPIES.

The recurrence of repetitive vomiting, lethargy and pallor were the 3 most frequently observed minor criteria. Lethargy and pallor are criteria with large variability in studies (from $3.8 \%^{13}$ to $88.3 \%^{7}$ for lethargy; from $14 \%^{24}$ to $98.7 \%^{13}$ for pallor). We did not find any hypothermia in FPIES histories. Hypothermia is indeed an uncommon symptom, from $6 \%$ in Spain-Italy ${ }^{14}$ to $10 \%$ in Australia. ${ }^{2,15}$ Some minor criteria (such as hypothermia, hypotension, pallor and lethargy) are difficult to identify during the in-depth family interviews, and even worse in retrospective reviews of medical records. ${ }^{14}$

We included patients suffering from acute and chronic presumptive FPIES if the history was compatible with the diagnosis of FPIES, as previously described. The hypothesis that this may affect our results is unlikely because general characteristics and the prognosis in children with confirmed and presumptive FPIES did not differ. Recent data demonstrated how the different FPIES diagnostic criteria proposed over time provide conflicting results in patients with a high clinical suspected likelihood of acute FPIES. ${ }^{14}$ Despite 
multiple reactions to the same offending food, one quarter of the cohort of Vazquez-Ortiz et al. ${ }^{14}$ did not meet the criteria from the "2017 consensus" ${ }^{5}$, especially when severity was mild, ${ }^{14}$ as was the case for us. Accordingly, we cross-referenced our 145 acute FPIES patients to other definitions. We found $61.4 \%$ of patients who fulfilled the Powell criteria modified by Sicherer $/ 1998,{ }^{25} 61.4 \%$ (up to $84.8 \%$ without the age criteria) according to Leonard/2012, ${ }^{26} 24.1 \%$ with Miceli Sopo's 2013 definition (up to $27.6 \%$ without the age criteria) ${ }^{27} 91.1 \%$ according to Lee/2017. ${ }^{16}$ Different phenotypes of FPIES may exist depending on geographic origins or culprit foods which could explain the variability of the symptoms previously described. ${ }^{14}$

Performing an OFC in the first year after the diagnosis resulted in an increased risk of failure, confirming that an OFC should generally be considered at least 12 months after the last reaction. ${ }^{6}$ For fish, one must be even more patient, because experts recommend postponing the performance of an OFC until 5 years of age or older, ${ }^{6}$ and testing tolerance to alternative fish to avoid an unnecessarily fish-free diet. ${ }^{22}$ Like Infante et al.,${ }^{22}$ we found that severe reactions at any moment were associated with a risk of longer duration of FPIES.

Limited data suggest that atypical FPIES with positive specific IgE is associated with delayed tolerance. ${ }^{6,20}$ This was not confirmed in our cohort, although sensitization (14.7\%) were similar compared to other studies (11.1\%-34\%). ${ }^{7,9,18,21}$ Eczema was found in $28.5 \%$ of patients, which is concordant with American and Australian cohorts where eczema is reported in $11 \%$ to $57 \%$ of patients with FPIES. ${ }^{5}$ Children with FPIES often have associated atopic conditions. ${ }^{4}$ Even if FPIES is not an atopic disease per se, this suggests that FPIES and other atopic comorbidities share common pathophysiology. ${ }^{28}$

We reported a lower frequency of multiple FPIES (5.6\%) than in the literature which is commonly reported at around $30 \% .{ }^{2,17,20,21}$ This may result from the use of stringent criteria for the diagnosis of FPIES and the retrospective design of the study. Despite medical charts studied, for multiple FPIES in $13.4 \%$ of cases as per other series, ${ }^{7,10,14,15}$ we only retained FPIES with a specific clinical description. The prevalence of multiple FPIES ranges from $5.1 \%{ }^{13}$ to $69.0 \%{ }^{18}$ These variations of prevalence could be explained by the fact that patients had been referred to tertiary centers in the case of multiple and more complex cases of FPIES. Secondly, it may be easier to diagnose multiple FPIES in children with a previous diagnosis of FPIES. ${ }^{5}$ Avoidance should be limited only to the confirmed offending foods. Supervised introduction allows for the prevention of unnecessary exclusion and overdiagnosis of multiple FPIES.

Our study had certain limitations. The decision to include patients with acute vomiting and only 2 minor criteria could be one such limit, as previously explained. The retrospective aspect of our study is another limitation, owing to missing data, and in particular in terms of the description of minor criteria and multiple FPIES. Familial history of atopic disease was self-reported, which leads to a typical bias of over-reporting allergic symptoms. In terms of further studies, researching a link between maternal feeding, mode of delivery, previous anti-acid treatment and frequency of antibiotic use and the occurrence of FPIES could be interesting, by exploring the field of gut dysbiosis.

\section{Conclusion}

In summary, we reviewed a large French cohort of children with FPIES. The main culprit foods were CM, hen's egg, and fish. The overall prognosis remained good, as half of the cohort had outgrown FPIES by 2 years of age. FPIES to seafood products and severe forms of FPIES were associated with delayed tolerance. IgE sensitization was not a risk factor for persistent FPIES.

Acknowledgments: Dr Challier Pierre, Dr Courbage Sophie, Dr De Boissieu Delphine, Dr Garcette Karine, Dr Lemale Julie, Dr Mamann Nathalie, Dr Pauliat-Desbordes Sylvie

\section{References}

1. Katz Y, Goldberg MR, Rajuan N, Cohen A, Leshno M. The prevalence and natural course of food proteininduced enterocolitis syndrome to cow's milk: A large-scale, prospective population-based study. J Allergy Clin Immunol . 2011;127(3):647-53.e1-3. doi:10.1016/j.jaci.2010.12.1105. 
2. Mehr S, Frith K, Barnes EH, Campbell DE. Food protein-induced enterocolitis syndrome in Australia: A population-based study, 2012-2014. J Allergy Clin Immunol . 2017;140(5):1323-1330.

3. Alonso SB, Ezquiaga JG, Berzal PT, et al. Food protein-induced enterocolitis syndrome: Increased prevalence of this great unknown - results of the PREVALE study. J Allergy Clin Immunol . 2019;143(1):430-433.

4. Ruffner MA, Wang KY, Dudley JW, et al. Elevated Atopic Comorbidity in Patients with Food ProteinInduced Enterocolitis. J Allergy Clin Immunol Pract . 2020;8(3):1039-1046.

5. Nowak-Wegrzyn AH, Chehade M, Groetch ME, Spergel JM, Wood RA, Allen K. International consensus guidelines for the diagnosis and management of food protein-induced enterocolitis syndrome: Executive summary - Workgroup Report of the Adverse Reactions to Foods Committee, American Academy of Allergy, Asthma \& Immunology. J Allergy Clin Immunol . 2017;139(4):1111-1126.e4.

6. Nowak-Wegrzyn A, Berin C, Mehr S. Food protein-induced enterocolitis syndrome. J Allergy Clin Immunol $\operatorname{Pr}$. 2020;8(1):24-35.

7. Diaz J, Espin B, Segarra O, et al. Food protein-induced enterocolitis syndrome: data from a multicenter retrospective study in Spain. J Pediatr Gastroenterol Nutr . 2019;68(2):232-236.

8. Ludman S, Harmon M, Whiting D, du Toit G. Clinical presentation and referral characteristics of food protein-induced enterocolitis syndrome in the United Kingdom. Ann Allergy Asthma Immunol . 2014;113(3):290-294.

9. Xepapadaki P, Kitsioulis NA, Manousakis E, Manolaraki I, Douladiris N, Papadopoulos NG. Remission Patterns of Food Protein-Induced Enterocolitis Syndrome in a Greek Pediatric Population. Int Arch Allergy Immunol . 2019;180(2):113-119.

10. Pérez Ajami RI, Carrión Sari SK, Aliaga Mazas Y, Calvo JB, Guallar Abadía MI. Experience in food protein-induced enterocolitis syndrome in a paediatric allergy clinic. An Pediatr . 2020;92(6):345-350.

11. Ocak M, Akarsu A egül, Sahiner UM, Soyer O, Sekerel BE. Phenotypes and natural history of food protein-induced enterocolitis syndrome in the east Mediterranean region. Allergy Asthma Proc . 2020;41(6):420-427.

12. Miceli Sopo S, Giorgio V, Iacono I Dello, Novembre E, Mori F, Onesimo R. A multicentre retrospective study of 66 Italian children with food protein-induced enterocolitis syndrome: Different management for different phenotypes. Clin Exp Allergy . 2012;42(8):1257-1265.

13. Douros K, Tsabouri S, Feketea G, et al. Retrospective study identified fish and milk as the main culprits in cases of food protein-induced enterocolitis syndrome. Acta Paediatr . 2019;108(10):1901-1904.

14. Vazquez-Ortiz M, Argiz L, Machinena A, et al. Diagnostic criteria for acute FPIES: What are we missing? J Allergy Clin Immunol Pract . 2020;8(5):1717-1720.e2.

15. Mehr S, Kakakios A, Frith K, Kemp AS. Food protein-induced enterocolitis syndrome: 16-year experience. Pediatrics . 2009;123(3):e459-64.

16. Lee E, Campbell DE, Barnes EH, Mehr SS. Resolution of acute food protein-induced enterocolitis syndrome in children. J Allergy Clin Immunol Pract . 2017;5(2):486-488.e1.

17. Lee E, Barnes E, Mehr S, Campbell D. An exploration of factors associated with food protein-induced enterocolitis syndrom: birth, infant feeding and food triggers. Pediatr Allergy and Immunol . 2021. doi:10.1111/pai.13448

18. Blackman AC, Anvari S, Davis CM, Anagnostou A. Emerging Triggers of FPIES: Lessons from a Pediatric Cohort of 74 Children in the US.Ann Allergy Asthma Immunol . 2019;122(4):407-411.

19. Su K-W, Patil SU, Stockbridge JL, et al. Food aversion and poor weight gain in food protein-induced enterocolitis syndrome: a retrospective study. J Allergy Clin Immunol . 2020;145(5):1430-1437. 
20. Caubet JC, Ford LS, Sickles L, et al. Clinical features and resolution of food protein-induced enterocolitis syndrome: 10-year experience. J Allergy Clin Immunol . 2014;134(2):382-389.

21. Ruffner MA, Ruymann K, Barni S, Cianferoni A, Brown-Whitehorn T, Spergel JM. Food Protein-induced Enterocolitis Syndrome: Insights from Review of a Large Referral Population. J Allergy Clin Immunol Pract . 2013;1(4):343-349.

22. Infante S, Perez-Pallise ME, Skrabski F, et al. Poor prognosis of food protein-induced enterocolitis syndrome to fish. Pediatr Allergy Immunol . 2020. doi:10.1111/pai.13430

23. Gonzalez-Delgado P, Caparros E, Moreno MV, et al. Clinical and immunological characteristics of a pediatric population with food protein-induced enterocolitis syndrome (FPIES) to fish. Pediatr Allergy Immunol . 2016;27(3):269-275.

24. Katz Y, Goldberg MR, Rajuan N, Cohen A, Leshno M. The prevalence and natural course of food protein-induced enterocolitis syndrome to cow's milk: A large-scale, prospective population-based study. $J$ Allergy Clin Immunol . 2011;127(3):647-653.

25. Sicherer SH, Eigenmann PA, Sampson HA. Clinical features of food protein-induced enterocolitis syndrome. J Pediatr . 1998;133(2):214-219.

26. Leonard SA, Nowak-Wgrzyn A. Clinical diagnosis and management of food protein-induced enterocolitis syndrome. Curr Opin Pediatr . 2012;24(6):739-745.

27. Miceli Sopo S, Greco M, Monaco S, Tripodi S, Calvani M. Food protein-induced enterocolitis syndrome, from practice to theory. Expert Rev Clin Immunol . 2013;9(8):707-715.

28. Adel-Patient K, Lezmi G, Castelli FA, et al. Deep analysis of immune response and metabolic signature in children with food protein induced enterocolitis to cow's milk. Clin Transl Allergy . 2018;8(38):1-19.

Table I : General characteristics of the population

Table II: Comparisons between cow's milk and the other culprit foods, in terms of age at the onset of the first symptoms, first OFC, and resolution

Table III: FPIES characteristics

Figure 1: Number of patients according to the offending foods

Milk: n=108; Hen's egg: $n=29$; Fish: $n=21$;Vegetables, legumes and fruits: $n=21$ (apple, apricot, avocado, banana, broccoli, cashew nuts, coconut $(n=2)$, cucurbits $(n=2)$, green beans, green peas, mushroom $(\mathrm{n}=2)$, peanut. pineapple, raspberry, soy, sweet potato $(\mathrm{n}=2)$, tomato); Cereals: $\mathrm{n}=8$ (maize, rice and rice hydrolysate $(\mathrm{n}=6)$, wheat); Meat: $\mathrm{n}=5$ (beef $(\mathrm{n}=3)$, chicken $(\mathrm{n}=2)$ ).

Figure 2: Overall Kaplan-Meier survival curve

Figure 3: Kaplan-Meier survival curves for milk, solid food, hen's egg, fish and likelihood of FPIES resolution by age and food

Milk: likelihood of FPIES resolution by 1 year of age: $5.6 \%$; by 2 years of age: $42.8 \%$; by 3 years of age: $70.9 \%$; by 5 years of age: $90.7 \%$ Solid foods: likelihood of FPIES resolution by 1 year of age: $2.5 \%$; by 2 years of age: $24.4 \%$; by 3 years of age: $52.7 \%$; by 5 years of age: $66.2 \% \mathbf{H e n}$ 's egg: likelihood of FPIES resolution by 1 year of age: $3.5 \%$; by 2 years of age: $40.0 \%$; by 3 years of age: $74.3 \%$; by 5 years of age: $87.1 \%$ Fish: likelihood of FPIES resolution by 1 year of age: $4.7 \%$; by 2 years of age: $14.3 \%$; by 5 years of age: $38.1 \%$; by 10 years of age: $56.7 \%$ 

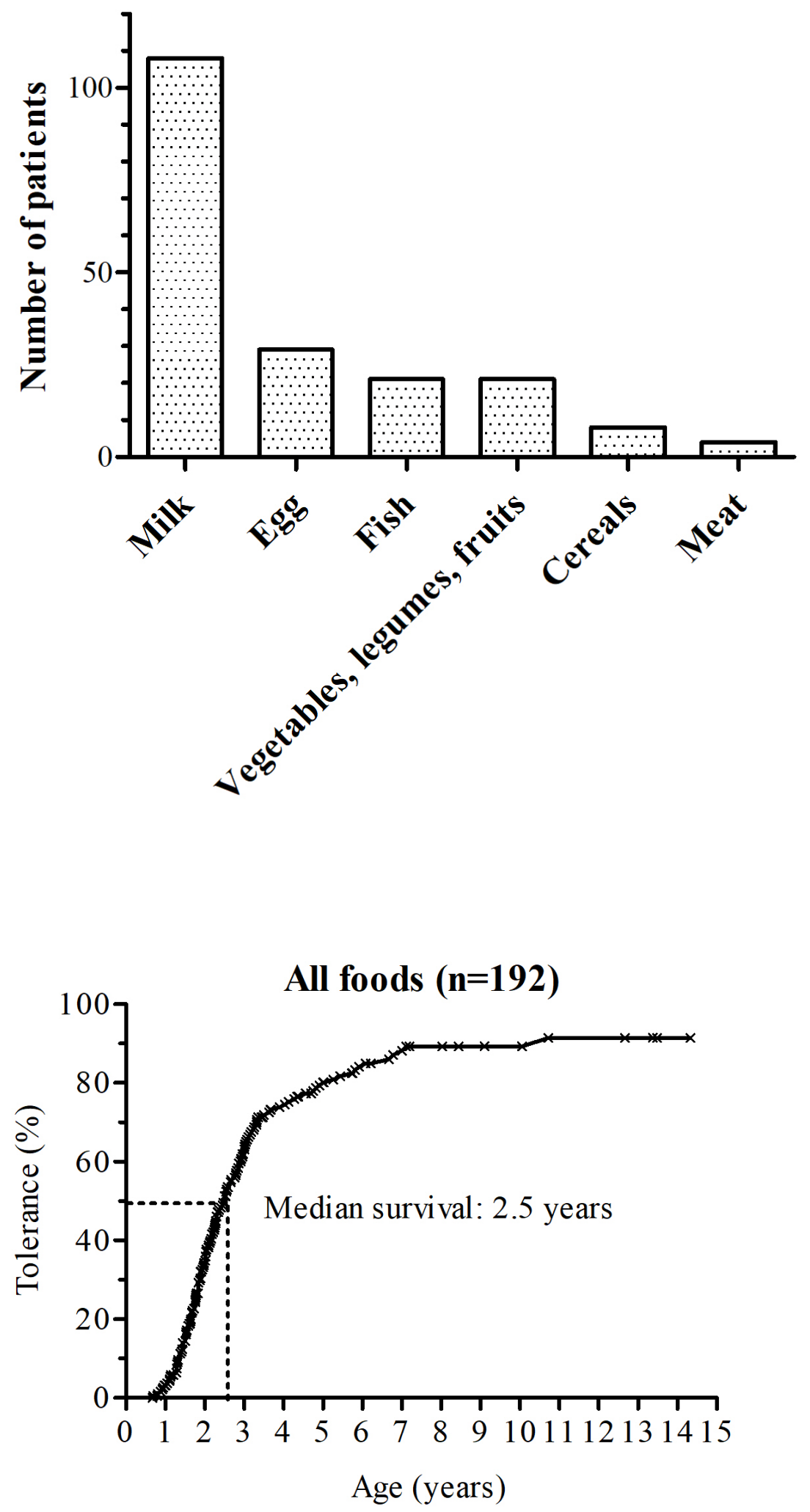

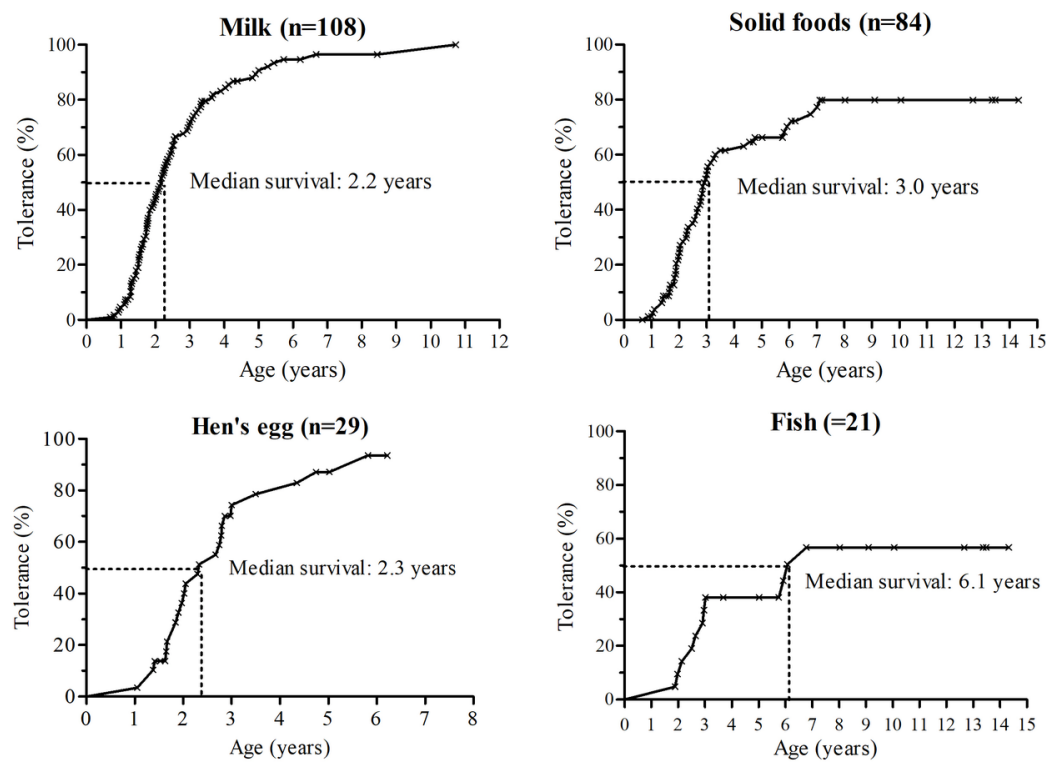

\section{Hosted file}

Table I.pdf available at https://authorea.com/users/408831/articles/518684-food-proteininduced-enterocolitis-syndrome-a-large-french-multicentric-experience

\section{Hosted file}

Table II.pdf available at https://authorea.com/users/408831/articles/518684-food-proteininduced-enterocolitis-syndrome-a-large-french-multicentric-experience

\section{Hosted file}

Table III.pdf available at https://authorea.com/users/408831/articles/518684-food-proteininduced-enterocolitis-syndrome-a-large-french-multicentric-experience 